\title{
Pneumatosis cystoides intestinalis
}

\begin{abstract}
Bei einer symptomatischen 67-jährigen Frau fand man während einer Screening-Koloskopie multiple, durchscheinende polypoide Schleimhautvorwölbungen in der Wand des Colon ascendens (Abb. a). In der Computertomografie des Abdomens stellte sich dieser Befund als ein Konglomerat von kleinen, bienenwabenartig konfigurierten luftgefüllten Bläschen in der Wand des rechten Kolons dar (Abb. b: Übersicht, Abb. c: axiale Schnittführung).
\end{abstract}

— Dieser Befund ist charakteristisch für einen Zustand, der als Pneumatosis cystoides intestinalis bezeichnet wird. Es handelt sich um ein Konglomerat von subserös und submukös gelegenen, luftgefüllten Bläschen, die als harmloser Befund ohne erkennbare Ursache gelegentlich angetroffen werden. Ähnliche Bilder entstehen aber auch bei schwerwiegenden Erkrankungen, zum Beispiel bei gastrointestinalen Infektionen, entzündlichen Darmerkrankungen, Mesenterialinfarkt oder malignen Erkrankungen, nach Organtransplantation oder bei der COPD.

In einzelnen Kasuistiken wurde auch der Gebrauch von alpha-GlukosidaseHemmern für die Entstehung dieses Phänomens verantwortlich gemacht. Man nimmt an, dass eine medikamentenbedingte exzessive Gasbildung zum Eintritt von Gas in die Darmwand führt.
Auch die hier vorgestellte Patientin verwendete den alpha-Glukosidase-Inhibitor Acarbose zur Behandlung ihres Typ-2-Diabetes. Ihr wurde geraten, diese Therapie zu beenden. Tatsächlich fanden sich bei einer Untersuchung drei Monate später keine Hinweise mehr für intramurale Luft im Bereich des Kolons.

H. S. FÜESSL =

\section{- S.-S. Wu, H.-H. Yen}

(Changhua Christian Hospital, Changhua, Taiwan; 91646@cch.org.tw): Pneumatosis cystoides intestinalis. New Engl. J. Med. 365 (2011) 8, e16

Die Gasblasen in der Kolonoskopie (a), der Abdomenübersichtsaufnahme (b) und im $C T$ (c).
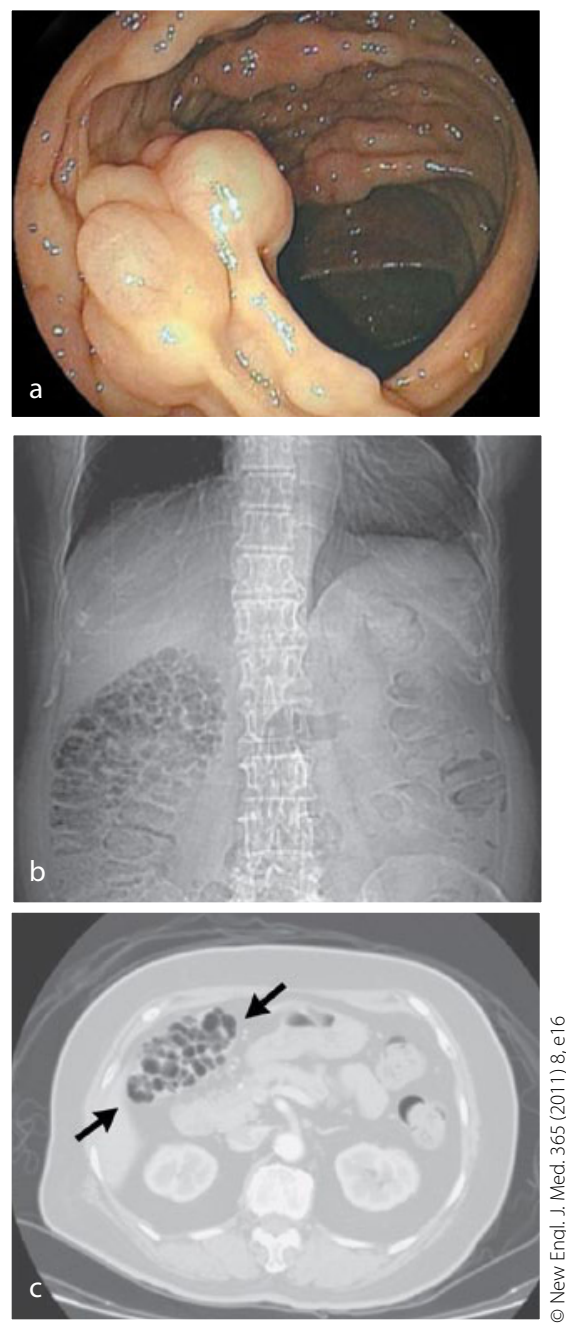

\section{Kopfbälle sollen Hirnschäden verursachen}

\section{Seit Jahren streiten Forscher um die Folgen des Kopfballspielens. Eine neue US-Studie offenbart Hirn- schäden bei Amateurfußballern, die besonders oft den Kopf einsetzen.}

- Forscher der Yeshiva University in New York untersuchten 38 Männer (Durchschnittalter 30,8 Jahre) die seit ihrer Kindheit Fußball spielten. Die Studienteilnehmer sollten angeben, wie oft sie im vergangenen Jahr Bälle mit dem Kopf gespielt hatten. Um die Auswirkungen der Kopfpässe zu messen, scannten die US-Forscher die Gehirne der Kicker mit der sogenannten diffusionsgewichteten Magnetresonanztomo- grafie (MRT). Diese macht besonders Nerven- und Hirngewebe sichtbar.

Die Ergebnisse zeigen: Kopfbälle bleiben nicht ohne Folgen. Männer mit mehr Kopfeinsatz wiesen Hirnschäden in fünf verschiedenen Bereichen auf, die unter anderem wichtig für Aufmerksamkeit, Gedächtnis und Verhaltenssteuerung sind. Die Veränderungen in den Fußballerköpfen ähneln Schäden, die Mediziner sonst nur bei SchädelHirn-Traumata zu sehen bekommen. Üblich sind solche Gehirnerschütterungen nach Verkehrsunfällen. Die Betroffenen haben dann häufig Gedächtnislücken, Schwindelgefühle oder Kopfschmerzen.

\section{Kommentar}

Die Menge macht's. Die Veränderungen im Gehirn treten erst auf, wenn die Sportler zwischen 1000 und 1500 Mal im Jahr mit dem Kopf zum Ball gehen. Kopfaktive Spieler, also jene mit mehr als tausend Kopfbällen pro Jahr, schnitten in Gedächtnistests und Koordinationsübungen schlechter $a b$, als weniger kopflastige Fußballer.

K. MALBERG = 